\title{
A survey of failed post-retained restorations
}

\author{
A. Peutzfeldt • A. Sahafi • E. Asmussen
}

Received: 16 January 2007 / Accepted: 25 June 2007 / Published online: 17 July 2007

(C) Springer-Verlag 2007

\begin{abstract}
Survival of endodontically treated, post-restored teeth depends on a multitude of factors, all of which are practically impossible to include in a randomized, controlled clinical study. The purpose of this survey was to characterize and analyze reported failures of post-retained restorations to identify factors critical to failure and to type of failure. A questionnaire was mailed to private practitioners in Denmark with a request to complete the questionnaire whenever a patient presented with a failed post-retained restoration. Information was gathered on factors related to the patient, the tooth, the restorative materials, and the techniques. Two-hundred and sixty questionnaires were collected from 171 practitioners over a 3-year period. Functioning time until failure varied between 3 months and 38 years. Mean survival time until failure was 11 years. Of the failed restorations, $61 \%$ had functioned for 10 years or less. Fracture of the tooth was the most common type of failure reported, followed by loosening of the post and fracture of the post. Tapered posts implied an increased risk of tooth fracture compared to loosening or fracture of the post, and the relative risk of tooth fracture increased with the functioning time until failure. Fracture of the post was more common among male than female patients. On the basis of this survey of failed
\end{abstract}

\footnotetext{
A. Peutzfeldt $(\bowtie) \cdot$ E. Asmussen

Department of Dental Materials, School of Dentistry, University of Copenhagen,

Nörre Allé 20,

2200 Copenhagen, Denmark

e-mail: apz@odont.ku.dk

\author{
A. Sahafi \\ Department of Oral Rehabilitation, School of Dentistry, \\ University of Copenhagen,
}

Copenhagen, Denmark
}

post-retained restorations, it was concluded that tapered posts were associated with a higher risk of tooth fracture than were parallel-sided posts.

Keywords Dowel $\cdot$ Fixed prosthodontics $\cdot$ Post .

Questionnaire · Type of failures

\section{Introduction}

Endodontically treated teeth have been reported to have shorter survival time than vital teeth $[14,20,29,33,35]$. This is believed to reflect that endodontically treated teeth are often structurally compromised because of a series of events: caries or trauma, endodontic therapy, and preparation for restorative procedures $[12,19,32,34,40,41,47-$ 49]. Thus, to minimize the negative influence on longevity, the restorative procedure of endodontically treated teeth calls for careful consideration of treatment alternatives.

In the case of minimal-remaining tooth substance, the retention of a crown has traditionally been provided by a core and the retention of the core by a post. Two fundamentally different techniques find widespread use for the construction of a post and core: (1) a post and core cast as a single unit and (2) a prefabricated post upon which a core is directly produced in, e.g., amalgam or resin composite. The first prefabricated posts on the market were made of stainless steel or gold-plated brass. Later, posts of titanium alloys became popular, and recent developments have introduced posts made of fiber-reinforced resin composite or ceramic. Simultaneously, adhesive dentistry, offering reliable bonding to tooth substance and to restorative materials via various pretreatments, has markedly progressed to widen the possibilities also for post and core treatment. 
As mentioned, the post serves to retain the restoration. However, the post should also serve to protect the remaining tooth structure. These two functions of endodontic posts may be evaluated by determining the retentive ability of the posts and the fracture resistance of endodontically treated teeth provided with post-retained restorations. The latter may also be indirectly determined by analysis of the stress-distributing characteristics of the posts. Postrelated factors that have been found to exert influence on retention of posts and protection of tooth structure include: shape, length, diameter, surface design, and stiffness of the post as well as the type of luting cement used.

As regard to post shape, parallel-sided posts provide better retention and less stress formation and increased fracture resistance than do tapered posts $[2,5,18,28,37$, $38,42,46]$. An increase in post length has a similar, positive effect $[2,5,7,8,17,42]$. However, some restrictions apply to post length. First, the apical seal of the endodontic restoration must be ensured through maintenance of 5-6 $\mathrm{mm}$ of apical gutta-percha $[1,24,53]$. Second, dentin in the apical third of teeth is often very thin. This not only increases the risk of parietal perforation, but it also weakens the tooth to a relatively high degree, thereby increasing the risk of root fracture. Little evidence is available as regard to the influence of post diameter. Consensus regarding retention seems to be that an increase in post diameter cannot be relied on as a measure to improve retention [5]. A study based on finite element analysis found that stress formation in the dentin decreased when post diameter was increased [2]. Conversely, another study showed that thinner posts provided increased resistance to fracture [48]. A consensus regarding fracture resistance seems to be that the root canal should not be uncritically enlarged, as decreasing the bulk of dentin weakens the tooth and reduces the resistance to fracture [5, $12,30]$. As regard to surface design, serrated posts provide better retention than smooth-sided posts, and threaded posts provide even better retention [5, 7, 37]. However, the superior retention of threaded posts, obtained by engaging in dentin, simultaneously is accompanied by increased stress formation within the root $[36,43]$ and thus by an increased risk of root fracture $[5,10,12,43]$. Post stiffness, which is a combination of post diameter and elastic modulus of the post material, is another important characteristic, but an unsettled discussion prevails as to optimal stiffness. On the one hand, insufficient stiffness will allow excessive distortion of the restoration at the margins during function, leading to breakdown of cement and risk of secondary caries. Moreover, a decrease in the elastic modulus of the post material has been found to increase stress formation in the root and to decrease fracture strength of the restored tooth $[2,23,38,39]$. Thus, low-modulus posts fail sooner or at lower stress values than do high- modulus posts. On the other hand, several studies have found that low-modulus posts display failures that cause little damage to the remaining tooth structure (loss of marginal seal, loss of retention, core fracture, and post fracture), while high-modulus posts are associated with a higher incidence of root fractures when they finally fail; that is, they cause more damage to the remaining tooth structure and often result in the extraction of the tooth involved [22, 23, 39, 47]. Retention of posts in the root canal is primarily sought through the use of a luting agent. Zinc phosphate cement has been the luting agent of choice for many years. The progress within adhesive dentistry and the advent of ceramic- and fiber-reinforced resin composite posts have prompted questions of the usefulness of resin cement for the luting of posts. Zinc phosphate cement provides retention by mechanical interlocking in irregularities in the surface of the root canal on one side and in the surface of the post on the other. After appropriate pretreatment of the respective surfaces, resin cements provide retention not only by mechanical interlocking but also by micromechanical and chemical adhesion. In vitro studies have found improved retention, less and more favorable stress formation, and improved fracture resistance with resin cements than with zinc phosphate cement $[2,6$, $25,31,51]$.

Other factors from those related to the post are of importance for success of post-retained restorations. Thus, researchers agree that the extent of remaining tooth structure is a key issue for fracture prognosis $[9,12,30$, 42, 47]. Another paramount factor is the ferrule effect: Teeth that allow preparation of a $1.5-2-\mathrm{mm}$ ferrule show superior fracture resistance [44, 45, 54].

The foregoing has shown that numerous factors influence the longevity of endodontically treated teeth provided with post-retained restorations and that it would be practically impossible to carry out a randomized controlled clinical trial that includes all relevant variables. Previous studies have shown annual failure rates related to post and core treatment of up to $5 \%[4,9,11,15,41,46]$. The purpose of this survey of failed post-retained restorations was to analyze reported failures in an attempt to identify factors that are critical to failure and to type of failure.

\section{Materials and methods}

A questionnaire was developed and piloted, and in June 2000 , it was posted, in five copies, to the members of the Danish Dental Association who worked in private practice (3,444 practitioners). The practitioners were asked to complete the questionnaire in case a patient presented with a failed post-retained restoration. Questions were asked about age and gender of the patient, tooth involved, number 
of posts, type, design, length, and diameter of the post(s), type of core, type of luting agent, type of restoration, height of any ferrule, degree of tooth destruction, functioning time until failure, and type of failure.

After 3 years, 260 questionnaires had been received, and the collection of questionnaires was terminated. Data were transferred to a computer and analyzed by use of the Statistical Analyzing System (SAS). Basic descriptive statistics including frequency distributions were performed. Selected data were analyzed by chi-squared tests and Fischer's exact probability tests $(\alpha=0.05)$. Cross tabulations were carried out to further characterize the data and to identify codeterminants of functioning time until failure and codeterminants of type of failure.

\section{Results}

The 260 questionnaires had been completed by 171 practitioners. The response rate per question varied between 26 and $98 \%$. Of the 260 patients, slightly more were female $(58 \%)$ than male $(42 \%)$. The age of the patients varied between 18 and 91 years, and the age distribution was statistically similar among female and male patients. The sample involved nearly three times as many maxillary teeth (74\%) than mandibular teeth $(26 \%)$. In the maxilla, there were fewer molars $(15 \%)$ than premolars $(38 \%)$ and incisors and canines $(47 \%)$, and in the mandible, there were fewer incisors and canines $(8 \%)$. Table 1 shows the distribution of the types of posts and cores: Slightly fewer teeth had been restored with cast post and cores than with prefabricated posts and direct cores. Of the 114 cast post and cores, $57 \%$ had been cast in a gold alloy, $25 \%$ in a silver-palladium alloy, and $18 \%$ were unaccounted for. Of the 130 prefabricated posts used in combination with a direct core, $51 \%$ were titanium posts, $20 \%$ were stainless steel posts, $8 \%$ were carbon fiber-reinforced resin composite posts, and $21 \%$ posts were either of an alternative or unknown material.

Of the 260 failed post-retained restorations, 54\% comprised tapered posts, $22 \%$ comprised parallel-sided posts, $20 \%$ comprised posts of a combined tapered-parallel design, and $4 \%$ comprised posts with a design that was not

Table 1 Distribution of type of post and cores among failed restorations

\begin{tabular}{ll}
\hline Type of post and core & Number \\
\hline Cast post and core & 114 \\
Prefabricated post with direct core & 130 \\
Prefabricated post with cast core & 5 \\
One-piece post crown & 7 \\
Total & 256 \\
\hline
\end{tabular}

accounted for. The majority of the cast posts $(76 \%)$ and of the stainless steel prefabricated posts $(73 \%)$ were tapered. The titanium posts were equally distributed between the three designs $(38,31$, and $31 \%)$, and the carbon fiberreinforced resin composite posts were either parallel sided $(50 \%)$ or of a combined design $(50 \%)$.

Of the 176 failed post-retained restorations that were specified as regard to the maximum diameter of the post, $68 \%$ comprised posts with a diameter equal to or less than one third of the diameter of the root, and $32 \%$ comprised posts with a diameter of more than one third. Of the 237 failed post-retained restorations that were specified as regard to length of post, $76 \%$ comprised posts with a length of more than $50 \%$ of the total length of the root. Table 2 shows the distribution of the posts as regard to type, material, and length of posts: For all posts, except those of stainless steel, the majority of the posts were of a length that was equal to or more than half the length of the root. For the stainless steel posts, $50 \%$ were shorter than half the length of the root.

Of the 130 teeth with a failed restoration that had been treated with a prefabricated post and a direct core, $29 \%$ had a core made in amalgam, 59\% a core made in resin composite, $3 \%$ a core made in glass ionomer cement, and $9 \%$ a core made in a material that was not accounted for. Amalgam had been used more often than resin composite for stainless steel posts ( 70 vs $30 \%$ ), whereas resin composite had been used more often than amalgam for titanium posts ( 84 vs $16 \%$ ) and, in all cases, for carbon fiber-reinforced resin composite posts.

Of the 260 failed post-retained restorations, $40 \%$ had been luted with zinc phosphate cement, $17 \%$ with glass ionomer cement, $10 \%$ with resin cement, and $33 \%$ posts with an agent that was not accounted for. The majority of the cast posts $(68 \%)$ and of the stainless steel prefabricated posts $(93 \%)$ had been luted with zinc phosphate cement. Most titanium posts had been luted with zinc phosphate cement $(48 \%)$ or glass ionomer cement $(37 \%)$. Of the carbon fiber-reinforced resin composite posts, $90 \%$ had been luted with resin cement and $10 \%$ with glass ionomer cement.

Of the 260 failed restorations $69 \%$ had a ferrule, $29 \%$ did not have a ferrule, and $2 \%$ were not accounted for. As regards the degree of tooth destruction before luting of the now failed post-retained restoration, only $25 \%$ restored teeth out of 260 were accounted for. In 47 cases, the whole clinical crown had been missing at the time of restoration, and in 18 cases, between one half and three fourths of the clinical crown had been missing.

Table 3 shows for how long the restorations had functioned in the mouth at the time of failure. The time of functioning of the 178 restorations that were accounted for varied between 3 months and 38 years. The mean survival 
Table 2 Distribution of posts of failed restorations as regards post type, post material, and post length in percent of root length

\begin{tabular}{|c|c|c|c|c|c|}
\hline \multirow[t]{2}{*}{ Type } & \multirow[t]{2}{*}{ Material } & \multicolumn{3}{|l|}{ Length } & \multirow[t]{2}{*}{ Tota } \\
\hline & & $15-49 \%$ & $50-74 \%$ & $75-90 \%$ & \\
\hline \multirow[t]{2}{*}{ Cast } & Gold & 9 & 39 & 12 & 60 \\
\hline & Silver-palladium & 3 & 18 & 8 & 29 \\
\hline \multirow[t]{3}{*}{ Prefabricated } & Titanium & 14 & 30 & 17 & 61 \\
\hline & Stainless steel & 13 & 11 & 1 & 25 \\
\hline & Carbon fiber & 0 & 7 & 2 & 9 \\
\hline Total & & 39 & 105 & 40 & 184 \\
\hline
\end{tabular}

time until failure was 11 years, and the median survival time was 8 years. Of the 178 restorations, $61 \%$ had functioned 10 years or less at the time of failure. Of the 260 restorations, $51 \%$ displayed fracture of the tooth, $30 \%$ displayed loosening of the post, $17 \%$ displayed fracture of the post, and $2 \%$ displayed a type of failure that was not accounted for.

Among the post-retained restorations that failed after a relatively short functioning time ( $0-10$ years) as compared to a relatively long functioning time (11-38 years) were: (1) significantly more parallel-sided and combined taperedparallel posts than tapered posts, (2) significantly more carbon fiber-reinforced resin composite prefabricated posts than titanium and stainless steel prefabricated posts, (3) significantly more cast silver-palladium posts than cast gold posts, (4) significantly more resin composite cores than amalgam cores, and finally (5) significantly more posts luted with resin cement or with glass ionomer cement than with zinc phosphate cement. These results are unexpected, and as the "Discussion" will argue, the results do not truly reflect factors critical to functioning time.

Several factors were significantly related to type of failure. (1) The frequency of tooth fracture was similar for female and male patients (51 vs 50\%) as was the frequency of loosened posts (36 vs 25\%), but the frequency of fractured posts was higher for male than for female patients (24 vs 13\%). (2) The shorter the post, the lower the frequency of post fracture (Table 4). (3) Tapered posts more often than parallel-sided and combined tapered-parallel posts displayed fracture of tooth (61 vs 39 and 41\%) and

Table 3 Distribution of failed post-retained restorations as regards functioning time until failure

\begin{tabular}{ll}
\hline Functioning time (years) & Number \\
\hline $0-1$ & 15 \\
$2-5$ & 50 \\
$6-10$ & 43 \\
$11-20$ & 43 \\
$21-38$ & 27 \\
Total & 178 \\
\hline
\end{tabular}

less often fracture of post ( 9 vs 30 and 31\%). (4) Stainless steel prefabricated posts more often than titanium prefabricated posts displayed fracture of the tooth (81 vs 36\%). (5) Teeth restored with amalgam cores displayed mainly tooth fractures $(70 \%)$, teeth restored with cast gold cores displayed mainly tooth fractures $(51 \%)$ or loosening of post $(35 \%)$, and teeth restored with resin composite cores displayed all three types of failure with almost similar frequency $(35,25$, and $40 \%)$. (6) More teeth in which the post had been luted with zinc phosphate cement displayed tooth fracture than teeth for which glass ionomer cement or resin cement had been used (54 vs 34 and 36\%). (7) Compared with the frequencies of post fracture and loosening of the post, the frequency of tooth fracture increased with increasing functioning time until failure, and correspondingly, restorations that failed early on showed an equal frequency of the three types of failure (Table 5).

\section{Discussion}

Five percent of the private practitioners that had been invited to participate in the survey did so. Possible explanations for this low response rate include the open invitation design, the relative extensive questionnaire, and the fact that the questionnaire could not be completed once and for all but had to be procured whenever a patient presented with a failed post-retained restoration. Considering that prosthodontics is not a registered specialty in Denmark, there is no reason to believe that the treatments

Table 4 Distribution of failed post-retained restorations as regards length of post and type of failure

\begin{tabular}{lllll}
\hline Length $(\mathrm{mm})$ & Failure & & Total \\
\cline { 2 - 4 } & $\begin{array}{l}\text { Fracture } \\
\text { of tooth }\end{array}$ & $\begin{array}{l}\text { Fracture } \\
\text { of post }\end{array}$ & $\begin{array}{l}\text { Loosening } \\
\text { of post }\end{array}$ & \\
\hline $2-5$ & 20 & 2 & 11 & 33 \\
$6-10$ & 77 & 20 & 47 & 144 \\
$11-20$ & 12 & 12 & 7 & 31 \\
Total & 109 & 34 & 65 & 208 \\
\hline
\end{tabular}


Table 5 Distribution of failed post-retained restorations as regards functioning time of restoration and type of failure

\begin{tabular}{lllll}
\hline Functioning time (year) & \multicolumn{2}{l}{ Failure } & \multicolumn{2}{l}{ Total } \\
\cline { 2 - 4 } & $\begin{array}{l}\text { Fracture } \\
\text { of tooth }\end{array}$ & $\begin{array}{l}\text { Fracture } \\
\text { of post }\end{array}$ & $\begin{array}{l}\text { Loosening } \\
\text { of post }\end{array}$ & \\
\hline $0-1$ & 5 & 4 & 6 & 15 \\
$2-5$ & 14 & 15 & 11 & 40 \\
$6-10$ & 18 & 8 & 17 & 43 \\
$11-20$ & 27 & 2 & 14 & 43 \\
$21-38$ & 18 & 3 & 5 & 26 \\
Total & 82 & 32 & 53 & 167 \\
\hline
\end{tabular}

provided by the participating practitioners were of another type or quality than those provided by private practitioners in general. The fact that the questionnaires were filled out by individual practitioners in their everyday environment and not by calibrated investigators in an optimal research facility explains that the response rate to each question was not $100 \%$ and also implies some uncertainty as to the validity of the answers, especially those that included an element of estimation, e.g., of post diameter. The abovementioned factors call for some caution when interpreting the results of the survey.

As regards age and gender, the patient sample is not only representative of the private practice patient population in Denmark as such but also similar to patient samples in previously published clinical studies of post-retained restorations $[9,27,46]$. These clinical studies also supply explanations for the present finding that more maxillary teeth, especially incisors and canines, than mandibular teeth presented with failed post-retained restorations: Not only are more maxillary teeth than mandibular teeth treated with posts $[9,11,26,46]$, but post-retained restorations in maxillary teeth have also been reported to fail relatively more frequently than similar restorations in mandibular teeth [46]. In particular, post-retained restorations in anterior maxillary teeth have been found to show high failure rates, presumably because of higher functional horizontal forces acting on the anterior teeth than on posterior teeth $[13,26,27,46]$.

The types of posts, cores, and cements used for the failed restorations, not only reflect that preferences vary among practitioners but also that the age of the restorations vary widely, as did the materials and treatments available at the time of restoration. Given the design of this survey, i.e., we have only considered restorations that have failed, we have no knowledge of the entire population of post-retained restorations. Thus, the survey does not allow distinction between an over-representation of a given material or treatment caused by outspread use and over-representation caused by poor longevity.
The length of time that the post-retained restorations had functioned before failure varied from 3 months to 38 years with a mean survival time until fracture of 11 years. In agreement with the findings of previous surveys of failed post-retained crowns $[21,50]$, there was a tendency to a relatively high initial failure rate. However, the proportion of restorations that failed during the first 10 years was lower in the present survey $(61 \%)$ than in the survey by Lewis and Smith (94\%) [21]. In the survey of Turner [50], only $17 \%$ had survived more than 5 years. The longer lifespan found in the present survey may reflect that the samples of the previous surveys included posts that were generally shorter and more often smooth and/or tapered than the posts of the present survey. These features are likely to have increased the prevalence of loosened posts at an early stage.

A number of specific types of posts or materials were found to have significantly high prevalence in the group of post-retained restorations that failed after a relatively short functioning time: carbon fiber-reinforced resin composite posts, posts cast in silver-palladium, parallel-sided and combined tapered-parallel posts, resin composite cores, and resin cement and glass ionomer cement. Some of these posts and materials are probably found in this group of restorations that failed after a short functioning time, not because they in fact are associated with short functioning time but because they have been on the market for a relatively short time compared with the alternatives and thus are over-represented in the total group of restorations with a short functioning time.

The most commonly reported type of failure was tooth fracture followed by loosening of the post and, finally, fracture of the post. This relative distribution is at odds with that of previous, retrospective studies, which found loosening of the post to be the most common type of failure [3, $21,46,50]$. Failures in the form of loss of retention are most often restorable, whereas tooth fractures are most often nonrestorable and lead to extraction of the tooth. It is possible that it was easier for the practitioner to remember to submit a questionnaire when a more drastic tooth fracture occurred than when a post had lost retention and had to be recemented. Such a situation would tend to underestimate the proportion of loosened posts. An alternative explanation is that the distribution between types of failure has indeed changed to reflect a decrease in the use of smooth and tapered posts.

Several factors were found to significantly influence the distribution between types of failures. One factor was gender of the patient: Whereas there were, relatively speaking, equally many male and female patients in the group of post-retained restorations that displayed tooth fracture or loosening of post, there were more male patients in the group of restorations that displayed post fracture. It 
may be that the greater bite forces exerted by men [16] not only increase the failure rate of post-retained restorations as such [46] but also predispose for fracture of the post. Another factor was post length: Failed shorter posts were associated with a lower prevalence of post fracture than were longer posts. This finding is not readily explained on the basis of stress analyses but may reflect that there was an over-representation of stainless steel posts and/or of tapered posts in the group of short posts: Stainless steel has a higher elastic modulus and is a stronger material than gold alloys and titanium alloys [52] and may thus be expected to withstand higher stresses. Tapered posts were associated with a higher prevalence of tooth fracture than were parallel-sided and combined tapered-parallel posts and with a correspondingly lower prevalence of post fracture. This significant tendency to fail because of tooth fracture confirms results of previous studies [42, 46]. Likewise, failed stainless steel posts were associated with a higher prevalence of tooth fracture than were titanium posts. This could be an indirect result of most stainless steel posts being short, having high elastic modulus, and having a tapered shape in contrast to most titanium posts being parallel sided. Teeth that failed and had been restored with amalgam cores displayed significantly more tooth fractures than teeth restored with cores of resin composite and cast gold post and cores. Because of intermediate mechanical properties, e.g. elastic modulus, of amalgam as compared to resin composite and gold alloy, mechanical properties cannot easily explain the high prevalence of tooth fracture. Instead, it is likely to be caused not by the amalgam core itself but by other factors that characterize the posts with which amalgam was used. Amalgam was the preferred core material for stainless steel posts, whereas resin composite was the preferred core material for titanium posts. As just mentioned, stainless steel posts were more often than other posts tapered, a factor that has also been shown to predispose for tooth fracture. The fact that zinc phosphate cement also seemed to predispose for tooth fracture may similarly be explained, not by inferiority of the material itself but by the posts with which it was used: A relatively higher percentage of posts cast in silver-palladium and of prefabricated stainless steel posts had been luted with zinc phosphate cement than with any other cement, and these two types of posts were associated with a high prevalence of tooth fracture. The final factor that was found to be significantly associated with type of failure was the length of time that the post-retained restorations had functioned until failure: The prevalence of tooth fracture increased with increasing functioning time until failure. This finding is in contrast to that of previous surveys of failed postretained crowns in which no correlation between type of failure and length of functioning time was found [21, 50]. The discrepancy can be explained by the fact that the present survey included teeth of a much wider range of functioning time until failure and higher mean age at failure.

This survey did not confirm the generally accepted, paramount influence on fracture prognosis of extent of remaining tooth structure and of a ferrule $[9,12,30,42,44$, $45,47,54]$. With regard to extent of remaining tooth structure, the reason is that an exceptionally low response rate did not allow statistical analysis of this parameter on a possible influence on functioning time and type of failure. The fact that the survey also did not find a significant influence of the existence of a ferrule calls for the following comments. First, the fact that most restorations were reported to have a ferrule reduced the probability that the statistical analysis would find a significant effect. Second, it is very positive to note that clinicians are aware of the importance of including a ferrule in the preparation. Third, the fact that restorations failed despite that the crowns had a ferrule points to the relevance of optimizing other elements in the restoration of an endodontically treated tooth.

\section{Conclusions}

The following are the conclusions derived from the study:

1. Fracture of the tooth was the most common type of failure among the failed post-retained restorations followed by loosening of the post and fracture of the post.

2. Compared with parallel-sided posts, tapered posts more often displayed fracture of the tooth and less often fracture of the post.

3. Post-retained restorations that had functioned for a long time before failure showed an increased risk of tooth fracture compared to loosening of the post and fracture of the post.

4. Fracture of the post was more common among male patients than among female patients.

Acknowledgments This study was supported by a grant from the Danish Dental Association. The authors thank the private practitioners who participated in the survey.

\section{References}

1. Abramovits L, Lev R, Fuss Z, Metzger Z (2001) The unpredictability of seal after post space preparations: a fluid transport study. J Endod 27:292-295

2. Asmussen E, Peutzfeldt A, Sahafi A (2005) Finite element analysis of stresses in endodontically treated, dowel-restored teeth. J Prosthet Dent 94:321-329

3. Balkenhol M, Wöstmann B, Rein C, Ferger P (2007) Survival time of cast post and cores: a 10-year retrospective study. J Dent $35: 50-58$ 
4. Bergman B, Lundquist P, Sjögren U, Sundquist G (1989) Restorative and endodontic results after treatment with cast posts and cores. J Prosthet Dent 61:10-15

5. Caputo AA, Standlee JP (1987) Biomechanics in clinical dentistry. Quintessence, Chicago, pp 185-203

6. Chan FW, Harcourt JK, Brockhurst PJ (1993) The effect of post adaptation in the root canal on retention of posts cemented with various cements. Aust Dent J 38:39-45

7. Colley IT, Hampson EL, Lehman ML (1968) Retention of post crowns. An assessment of the relative efficiency of posts of different shapes and sizes. Br Dent J 124:63-69

8. Cooney JP, Caputo AA, Trabert KC (1986) Retention and stress distribution of tapered-end endodontic posts. J Prosthet Dent 55:540-546

9. Creugers NHJ, Mentink AGM, Fokkinga WA, Kreulen CM (2005) 5-year follow-up of a prospective clinical study on various types of core restorations. Int J Prosthodont 18:34-39

10. Eckerbom M, Magnusson T, Martinsson T (1991) Prevalence of apical periodontitis, crowned teeth and teeth with posts in a Swedish population. Endod Dent Traumatol 7:214-220

11. Ellner S, Bergendal T, Bergman B (2003) Four post-and-core combinations as abutments for fixed single crowns: a prospective up to 10-year study. Int J Prosthodont 16:249-254

12. Fernandes AS, Dessai GS (2001) Factors affecting the fracture resistance of post-core reconstructed teeth: a review. Int J Prosthodont 14:355-363

13. Fox K, Wood DJ, Youngson CC (2004) A clinical report of 85 fractured metallic post-retained crowns. Int Endod J 37:561-573

14. Hämmerle CHF, Ungerer MC, Fantoni PC, Bragger U, Burgin W, Lang NP (2000) Long-term analysis of biologic and technical aspects of fixed partial dentures with cantilevers. Int J Prosthodont 13:409-415

15. Hatzikyriakos AH, Reisis GI, Tsingos N (1992) A 3-year postoperative clinical evaluation of posts and cores beneath existing crowns. J Prosthet Dent 67:454-458

16. Helkimo E, Carlsson GE, Helkimo M (1977) Bite force and state of dentition. Acta Odontol Scand 35:297-303

17. Holmes DC, Diaz-Arnold AM, Leary JM (1996) Influence of post dimension on stress distribution in dentin. J Prosthet Dent 75:140-147

18. Isidor F, Brøndum K (1992) Intermittent loading of teeth with tapered, individually cast or prefabricated, parallel-sided posts. Int J Prosthodont 5:257-261

19. Leary JM, Aquilino SA, Svare CW (1987) An evaluation of post length within the elastic limits of dentin. J Prosthet Dent 57:277-281

20. Leempoel PJ, Kayser AF, van Rossum GM, de Haan AF (1995) The survival rate of bridges. A study of 1674 bridges in 40 Dutch general practices. J Oral Rehabil 22:327-330

21. Lewis R, Smith BGN (1988) A clinical survey of failed post retained crowns. Br Dent J 165:95-97

22. Manocci F, Ferrari M, Watson TF (1999) Intermittent loading of teeth restored using quartz fiber, carbon-quartz fiber, and zirconium dioxide ceramic root canal posts. J Adhes Dent 2:153-158

23. Martinez-Insua A, da Silva L, Rilo B, Santana U (1998) Comparison of the fracture resistances of pulpless teeth restored with a cast post and core or carbon-fiber post with a composite core. J Prosthet Dent 80:527-532

24. Mattison GD, Delivanis PD, Thacker RW, Hassell KJ (1984) Effect of post preparation on the apical seal. J Prosthet Dent 51:785-789

25. Mendoza DB, Eakle WS, Kahl EA, Ho R (1997) Root reinforcement with a resin-bonded preformed post. J Prosthet Dent 78:10-15

26. Mentink AGB, Meeuwissen R, Käyser AF, Mulder J (1993) Survival rate and failure characteristics of the all metal post and core restoration. J Oral Rehabil 20:455-461
27. Naumann M, Blankenstein F, Kiessling S, Dietrich T (2005) Risk factors for failure of glass-reinforced composite post restorations: a prospective observational clinical study. Eur J Oral Sci 113:519524

28. Nissan J, Dmitry Y, Assif D (2001) The use of reinforced composite resin cement as compensation for reduced post length. J Prosthet Dent 86:304-308

29. Palmqvist S, Söderfeldt B (1994) Multivariate analyses of factors influencing the longevity of fixed partial dentures, retainers, and abutments. J Prosthet Dent 71:245-250

30. Peroz I, Blankenstein F, Lange KP, Naumann M (2005) Restoring endodontically treated teeth with posts and cores - a review. Quintessence Int 36:737-746

31. Peters MCRB, Poort HW, Farah JW, Craig RG (1983) Stress analysis of a tooth restored with a post and core. J Dent Res 62:760-763

32. Pontius O, Hutter JW (2002) Survival rate and fracture strength of incisors restored with different post and core systems and endodontically treated incisors without coronoradicular reinforcement. J Endod 28:710-715

33. Randow K, Glantz PO, Zoger B (1986) Technical failures and some related clinical complications in extensive fixed prosthodontics. An epidemiological study of long-term clinical quality. Acta Odontol Scand 44:241-255

34. Reeh ES, Douglas WH, Messer HH (1989) Stiffness of endodontically-treated teeth related to restoration technique. J Dent Res 68:1540-1544

35. Reuter JE, Brose MO (1984) Failures in full crown retained dental bridges. Br Dent J 157:61-63

36. Ross RS, Nicholls JI, Harrington GW (1991) A comparison of strains generated during placement of five endodontic posts. J Endod 17:450-456

37. Sahafi A, Peutzfeldt A, Asmussen E, Gotfredsen K (2004) Retention and failure morphology of prefabricated posts. Int $\mathrm{J}$ Prosthodont 17:307-312

38. Sahafi A, Peutzfeldt A, Ravnholt G, Asmussen E, Gotfredsen K (2005) Resistance to cyclic loading of teeth restored with posts. Clin Oral Investig 9:84-90

39. Sidoli GE, King PA, Setchell DJ (1997) An in vitro evaluation of a carbon fiber-based post and core system. J Prosthet Dent 78:5-9

40. Sorensen JA (1988) Preservation of tooth structure. J Calif Dent Assoc 16:15-22

41. Sorensen JA, Martinoff JT (1984) Intracoronal reinforcement and coronal coverage: a study of endodontically treated teeth. J Prosthet Dent 51:780-784

42. Sorensen JA, Martinoff JT (1984) Clinically significant factors in dowel design. J Prosthet Dent 52:28-35

43. Standlee JP, Caputo AA, Holcomb JP (1982) The Dentatus screw: comparative stress analysis with other endodontic dowel designs. J Oral Rehabil 9:23-33

44. Stankiewicz NR, Wilson PR (2002) The ferrule effect: a literature review. Int Endod J 35:575-581

45. Tan PLB, Aquilino SA, Gratton DG, Stanford CM, Tan SC, Johnson WT, Dawson D (2005) In vitro fracture resistance of endodontically treated central incisors with varying ferrule heights and configurations. J Prosthet Dent 93:331-336

46. Torbjörner A, Karlsson S, Ödman PA (1995) Survival rate and failure characteristics for two post designs. J Prosthet Dent 73:439-444

47. Torbjörner A, Fransson B (2004) A literature review on the prosthetic treatment of structurally compromised teeth. Int $\mathrm{J}$ Prosthodont 17:369-376

48. Trabert KC, Caputo AA, Abou-Rass M (1978) Tooth fracture- a comparison of endodontic and restorative treatments. J Endod $4: 341-345$ 
49. Trope M, Maltz DO, Tronstad L (1985) Resistance to fracture of restored endodontically treated teeth. Endod Dent Traumatol $1: 108-111$

50. Turner CH (1982) Post-retained crown failure: a survey. Dent Update 9:221-229

51. Utter JD, Wong BH, Miller BH (1997) The effect of cementing procedures on retention of prefabricated metal posts. J Am Dent Assoc 128:1123-1127
52. van Noort R (2002) Introduction to dental materials. Mosby, London

53. Wu MK, Pehlivan Y, Kontakiotis EG, Wesselink PR (1998) Microleakage along apical root fillings and cemented posts. J Prosthet Dent 79:264-269

54. Zhi-Yue L, Yu-Xing Z (2003) Effects of post-core design and ferrule on fracture resistance of endodontically treated maxillary central incisors. J Prosthet Dent 89:368-373 